This item was submitted to Loughborough's Research Repository by the author.

Items in Figshare are protected by copyright, with all rights reserved, unless otherwise indicated.

\title{
Youth in motion: spatialising youth movement(s) in the social sciences
}

PLEASE CITE THE PUBLISHED VERSION

http://dx.doi.org/10.1080/14733285.2013.779840

PUBLISHER

(C) Taylor \& Francis

VERSION

AM (Accepted Manuscript)

\section{PUBLISHER STATEMENT}

This work is made available according to the conditions of the Creative Commons Attribution-NonCommercialNoDerivatives 4.0 International (CC BY-NC-ND 4.0) licence. Full details of this licence are available at: https://creativecommons.org/licenses/by-nc-nd/4.0/

\section{LICENCE}

CC BY-NC-ND 4.0

\section{REPOSITORY RECORD}

Collins, Rebecca, James Esson, Caitlin O. Gutierrez, and Adefemi Adekunle. 2019. "Youth in Motion: Spatialising Youth Movement(s) in the Social Sciences". figshare. https://hdl.handle.net/2134/17414. 
Citation: Collins, Rebecca, James Esson, Caitlin O'Neill Gutierrez, and Adefemi Adekunle. 2013. “Youth in Motion: Spatializing Youth Movement(s) in the Social Sciences." Children's Geographies 11 (3): 369-76.

DOI:10.1080/14733285.2013.779840.

Version: Accepted for publication

Please cite published version 


\section{Introduction}

"Youth in Motion: Spatializing Youth Movement(s) in the Social Sciences" was a one-day interdisciplinary workshop convened by the University College London (UCL) Youth Geographies Research Group (YGRG) on Thursday $16^{\text {th }}$ June 2011 . The workshop attracted an international audience with participants from institutions in France, Finland, Italy, Canada and Australia, as well as around the UK. Although all attendees worked with youth in an academic context, many were also experienced youth work practitioners. Our primary objective was to provide an opportunity for social scientists working with youth in a diverse range of disciplinary contexts to consider how research accommodates the notion of movement(s) when exploring the spaces, places and everyday experiences of young lives. In this brief report we aim to present some of the key themes that emerged over the course of the workshop and connect these with recent work asking "where next?" for geographical research with youth.

Young people's lives have been firmly on the geographical agenda since the publication of Skelton and Valentine's Cool Places: Geographies of Youth Cultures (1998), which emphasised the potential for young lives to inform wider geographical debates. Recent research with youth has continued to offer unique perspectives on social and spatial issues at every scale from the local to the global, and the growing number of research groups and journals that cover youth research in the social sciences testifies to this. In recent months young lives have also been the focus of growing popular attention, particularly in developed nations, as the global economic crisis bites harder and opportunities for the young seem to dwindle further. This has resulted in protests about cuts to education, employment and social welfare across the globe and, in the UK, reached crisis point in the riots of August 2011 where young people, rightly or wrongly, were singled out as the protagonists.

While contemporary international economic and political events will certainly provide ample research material for future youth research, the issues they raise chime with a movement within youth geographies to re-interrogate the nature and meaning of "youth". Much extant research has looked "out" into young people's worlds, attempting to explore the world from their perspective, but more recently, scholars have begun to look inwards at the conceptualisations and framings that shape research with youth and contribute to defining questions about their lives. Part of this re-evaluation has forced youth researchers to confront the uncomfortable task of problematizing the extent to which "youth geographies" as a sub-discipline has contributed to reinforcing expectations and damaging stereotypes of the very population which is its focus (see, for example, Hopkins 2007; Weller 2006).

Attempts to move away from the static definitions of youth that have tended to underpin these narrow definitions have instead been characterised by a focus on fluidity and transition. Attention has shifted to the socio-spatial relations that characterise this portion of the life phase and the structure-agency negotiations that shape young people's navigation through them (Evans 2008; Jeffrey 2010, 2011). Hopkins and Pain (2007) suggest moving towards relational geographies of age, rather than defining enquiry based on arbitrary boundaries between life stages. Such an approach may help to liberate young people from the constraints of lifephase-based stereotypes and offer more conceptual freedom for the expression and understanding of their experiences. 
Recent discussions of "what now?" - or, perhaps more appropriately, "where now?" - for youth geographies have also been characterised by a tension surrounding the balance between theoretical development and empirical grounding. Horton and Kraftl (2005; 2006), for example, have argued for "more than usefulness" in youth research; that it should strive to connect with and advance intellectual enquiry beyond what might be immediately "useful" in terms of public policy, social action or young people's lives. At the same time, there exists an obligation to attend to the ethics of research with vulnerable or previously-excluded populations, and as such we have witnessed the growth of participatory methodologies that attempt to bring young people into the heart of research enquiries and place the power in their hands to "analyze and transform their own lives" (Cahill 2007, p. 297). Hopkins and Pain (2007) have suggested that participatory approaches offer scope for both "usefulness" and theoretical development, but, as discussion at the Youth In Motion workshop made clear, the degree to which these two should be balanced remains up for debate.

For the most part, these emerging perspectives on youth research tend to share three important concerns. First, they are rooted in an understanding of young people's expressions of agency as mobile, shifting, embodied - and often structurally bounded - in a wide variety of sociospatial settings, in such a way as to move beyond restrictive stereotypes and attend to their current position within a longer life trajectory. Secondly, they raise questions around what exactly constitutes "useful" research to young people, and the extent to which researchers should accommodate or prioritise this. And thirdly, they all call for a reinvigorated commitment to communicating understanding of young people's worlds beyond the discipline of geography. As Evans (2008) notes, while much youth research is conducted by geographers through a geographical conceptual lens, there are equally rich resources beyond geography that we regularly draw on and should speak back to - beyond our own discipline to other social sciences and beyond the academy to the public policy discourses in which young people are often positioned at the centre.

It is this dynamic interdisciplinary landscape that formed the backdrop to "Youth in Motion".

\section{Youth in motion}

Taking notions of movement, motion and mobility in their broadest senses and at a variety of scales, the reach of the workshop was deliberately framed to encompass dialogue around seven interlocking themes:

1. young bodies and corporeality;

2. spatial freedom and restriction;

3. travel and migration;

4. emotional and developmental transition;

5. youth subjectivities and narratives in flux;

6. socio-economic and cultural inequalities of participation and engagement;

7. contested spaces of belonging and exclusion.

The workshop was structured to provide a collaborative forum for the exchange of knowledge, ideas and experiences of researchers working in a variety of national and international contexts, and with disciplinary foci that shared an interest in youth movement(s). To this end, the format of the day did not follow the traditional conference structure of presentation and questions but deliberately employed a more discursive and relaxed composition. By using a blog (youthinmotion.blogspot.com) to publicise the 
event, disseminate prior readings and familiarise participants with the major themes of the day, we attempted to set a tone of shared enquiry and to promote dialogue between participants in advance as well as facilitate on-going interaction beyond the event.

The productivity of the 'breakout sessions' in the afternoon were testament to the experimental nature of the workshop. Participants had submitted short position papers in advance of the workshop outlining some of the key questions underpinning their own research. Discussion groups were arranged according to commonalities between these papers. In four groups of six to eight, participants discussed the multiple expressions of youth agency that had arisen in their own research, sharing the approaches and linkages they had found useful in their respective projects. The four groups, each chaired by one of the organisers, were loosely structured by the shared interests of its members: two groups' discussions focused on conceptual issues; one group's on practical methodological concerns; and the fourth group focused on ethical issues.

The first group, chaired by Caitlin O'Neill, focussed on issues of power, authority and young people's agency on a range of vertical and horizontal spatial axes. Whilst it may be increasingly accepted that socio-economic structures do not operate solely in a top-down linear manner in relation to young people, participants considered how, if young people are agentic and choose to engage in relational power performances at various levels (from the international level to the local to the body), researchers can incorporate this into research with them. Furthermore, how might researchers' use of hierarchical and traditionally controlling structures such as educational establishments to access young research participants preclude or influence the kinds of discussions about agency and subversion that a young person engages in or is willing to divulge? Discussion also explored the impact of young people's direct action across the world in recent months, such as the events surrounding the 'Arab Spring' and the anti-austerity protests in the UK, on wider socioeconomic and political climates, particularly the way in which it demands that observers pay attention to the complex colonial legacies affecting the young in non-Western and postcolonial societies. The group considered how non-'youth', or 'adults', can learn from such forms of risk-taking and social justice activism in the face of shifts within Western nations towards social and economic conservatism. Can youth movements and resistance to hegemonic forms of power be rethought of as exemplary to the rest of society?

Discussion then moved to examine how the intensification of national securitisation agendas impacts upon the kinds of spatial life patterns that young people reproduce. It was agreed that the process whereby streets and public space are kept 'safe' equates to maintaining them free of 'youth'. Throughout the session, participants incorporated ideas about how young people negotiate or straddle this boundary between (in)visibility. Particularly evocative were two participants' empirical projects that exposed how fraught and delicate young people's negotiation of their visibility may be when they are 'illegal' or 'undocumented' immigrant youth - in their case foregrounding their need to make themselves less visible to certain policing structures. In contrast, another participant gave an example from her fieldwork of young white men deliberately making themselves visible at school as transgressive actors through smoking practices during recreation, whilst 
still being able to occupy a 'safe' and respectable image within formal class time. Above all, the group agreed that young people navigate social structures with personalised and context-specific expressions of agency - and as such we as researchers must interact with young people in necessarily diverse and flexible ways.

The second group discussion, chaired by Rebecca Collins, similarly evolved around young people's experiences of (in)visibility, and, in particular, their strategies for moving between visible and invisible. Drawing on a varied range of empirical projects, the group explored young people's movements into, within and between places and practices of (in)visibility, and the ways in which these transitions are initiated by choice or necessity. Discussion focussed on how specific practices come to be employed in order to facilitate or challenge (in)visibility and the ways in which these expressions of agency form the basis of young people's attempts to improve their lives. The appropriation of public space for specific practices was one such example; the playing of capoeira and parkour in Italy served to allow young second generation migrants to exert their own definitions of place through conspicuous embodied practices. Young people were noted as also increasingly inhabiting virtual spaces: focusing specifically on the concerns of LGBT youth, the group considered these young people's negotiations between what may sometimes be the necessity of invisibility within their material world but the greater freedom to be visible permitted by the virtual realm. It was noted in particular the extent to which the growth of technologies such as smartphones has expedited human ability to be both (in)visible and situated within multiple (im)material places simultaneously.
A third perspective considered the changing meaning of spaces according to young people's choices about their (in)visibility by drawing on two projects: one on young people's mental health, the other on their alcohol consumption. As the young people recovering from mental illness felt more comfortable being visible, the public transport spaces that they previously associated with danger and anxiety were reframed as safe and socially inclusive places. For the young consumers of alcohol, their shifting (in)visibility was structured by the equally shifting (in)visibility of adults in their communities. As pub- or club-going adults move into town centres during the evening, young people are displaced and obliged to relocate themselves in alternative 'spaces for drinking' on the margins of 'adult' alcohol consumption practices. In concluding, the group felt that important questions remain around the contingent making and meaning of both place and practice in young people's worlds - how, for instance, do places (and their associated structures) shape young people's engagement with specific practices? And how do practices come to help them make and attach distinct meanings to the places they inhabit?

The third session, chaired by James Esson, centred on the conceptual and methodological challenges that arise when doing research with young people in the global south. Initial discussions addressed common concerns amongst group participants, namely positionality, reflexivity and subjectivity. One participant sought to undertake selfcritical introspection with the discussion group before embarking on an ethnographic study of the Rwandan educational system. Drawing on examples from their own research and existing literature, several group members highlighted the 'irresolvable unknowability' of one's own position or that of others. The 
methodological trepidation experienced by participants was considered reflective of concerns that researchers from the global north often reproduce existing patterns of domination through research processes and ensuing output. Despite the growing prevalence of participatory approaches and methods, it was felt that researchers of youth in the global south tend to consult and interact with young people mostly during the data collection phase, but how much involvement are young people granted once a researcher begins data analysis? It was also noted that this was a simple yet subtle example of how researchers working with young people can, and often do, become embroiled and complicit in the structural processes they are investigating. As academics it is likely that we engage more frequently with theoretical abstraction than the participants we are dealing with, but the group asked, are we doing participants a disservice by 'doing' the abstraction for them? How can we engage in deeper participatory geographies, one that encourages participation from young people at all stages of research, from inception through data collection and analysis to publication? Do we need to?

Participants also discussed the significant progress made by researchers of young people in addressing lay discourses, yet it was felt that certain young people or types of bodies are still significantly under-researched. One participant touched upon the difficulties they were facing finding literature on young people with disabilities/impairments living in the global south. This led the group to consider how best to grasp the subjective experiences of disabled/impaired young people that is sensitive to geographical specificity. How can/should we conceptualize the social, political and economic ramifications of disability? How are these and other factors shaping the spatially embodied practices of young disabled people in the global south? Given the technological innovations at the modern researcher's disposal, we are perhaps better placed to start addressing these questions, and to engage with disabled young people on terms that are both participatory and elucidating.

In the fourth session, chaired by Femi Adekunle, debate orbited around two main points the practice of becoming mobile and, since the session was populated by researchers in certain institutional interstices (schools, youth clubs and informal spaces), the practical and ethical balances that must be struck when out in the field. Much discussion focused on how to capture stillness as an active engagement with space. It was recognised how, at a point when identity was being (re)constructed, staying in the same place was an act that demanded as much interpretation as movement. Indeed, one participant described how, in the small rural area of one of their former fieldwork sites, the act of staying in one place in the absence of jobs was an action that could be analysed on multiple levels. Thus, sustained focus on space allowed room to perceive other aspects of everyday lived youth experience. Another participant described how, in a skateboard park, there was an unconscious and inadvertent timetable: truants and older kids (both boys and girls) used it in the early morning and afternoon; school children in the late afternoon and older teenagers and even adults in the evening, creating a social hierarchy in the same space. The various competing temporalities - day of the week; time of day; season; traffic pattern - all hinted at the different social-temporal rhythms that run through young lives. 
Other practical methodological issues arose in the course of discussion - participants shared how the use of equipment to capture mobility changed the participant relationship in certain easily noticeable ways. The use of video cameras placed responsibility (especially after training) on the participant and usually meant a greater commitment to the project. Even disposable cameras had their place and the material representation of trust that a physical object made tangible - be it a phone, a camera or a diary sometimes had surprising implications. Debate on the ethics of research with youth coalesced around the view that ethics should not be a bureaucratic obstacle to overcome but should be the space allocated in a research methodology for sincere expression of participant and researcher expectations. There were lacunas within this: could or should a place be named if there were potential negative connotations? How might it be possible to construct a participatory methodology subtle enough to harvest apathy and subversion? In what ways is it most appropriate and most practical for researchers to ethically engage with their participants' youth? And, whilst viewing young people as co-participants, how should we as researchers deal with the fact that they might be expressing views (such as racist, homophobic or criminal) that in the future they might later regret? After all, the various institutional guises (especially around youth work) represented at the workshop were based around sustaining a long-standing relationship with young people. How might youth/case workers or teachers marry their research incarnation with a potential youth advocacy role?

\section{Speaking back, moving forward}

The final session of the day invited workshop participants to reassemble as one group to analyse the findings from the breakout discussions. The session sought to identify key themes and possible directions for future research within the social sciences. The key points that emerged included:

1. The extent to which information and communication technologies have made investigations of young people's production of place more complex - but also potentially illuminating in new ways. What is the relationship between virtual and material space?

2. Questions of temporality - the rhythm of young people's lives; the impacts of seasonality; whether, in becoming defined by the ages of their inhabitants, spaces can be said to have 'ages' of their own; as well as the temporality of the research process itself.

3. Forms of youth marginalisation that are not characterised by disempowerment, such as young people actively removing themselves from certain spaces.

4. Youth in the global north are facing exposure to structural challenges experienced by young people in the global south for some time. How can this be explored and theorised in such a way as to be sensitive to the unique contexts of each?

5. How is it possible to reconcile policy-focused interests on the social, physical and emotional wellbeing of young people with academic conceptual and methodological interests?

Despite the variety of topics discussed during the breakout and afternoon sessions, two overarching themes came to the fore; conceptualizing youth in a global context, and the tension between useful and 
more than useful research. In this conclusion, we address these issues respectively.

Contemporary conceptualisations and definitions of youth acknowledge its fluid and multifaceted nature. But much of this work is based on empirical studies conducted in the 'global north'. This becomes problematic if, as evidenced at this workshop, youth becomes an uncontested category with definitions derived from research in the 'global north' implicitly attributed default status. The shift away from static definitions of youth and their resultant narrow definitions to more relational geographies of age is a productive one; however, a notable direction for future research will be the exploration and theorization of youth in a manner better able to accommodate geographical specificity. During the workshop, one participant's research highlighted how young males in Ghana were using bureaucratic inefficiencies to manipulate their ages on travel documents. It was argued that doing so allowed them to avoid the negativity associated with being older in both a competitive local and global job market. They were therefore able to continue attracting oversees employers in their pursuit to migrate and escape economic difficulties in Ghana. Although challenging, it was felt that attempting to unpack such cases where young people traverse the structure-agency binary in unique ways might prove exemplary to wider debates. This aim resonates with Jeffrey's claim, that "conceptually, consideration of children and youth offers a basis for re-evaluating some of the common terms - such as structure, agency and participation - that form part of the intellectual currency of human geography" (2010, p.497) - as well as the social sciences more generally.

A glance at the five key concerns that emerged from the afternoon session reveals a diverse set of questions, which could not easily be separated into 'useful' versus 'more than useful' projects. We noted in the introduction of this report recent thought provoking articles on the balance between theoretical development and empirical grounding, and this proved a recurrent discussion point amongst participants. It was evident that Horton and Kraftl's (2006, p.69) call for researchers interested in the study of young people to engage more frequently with emergent theoretical, philosophical and conceptual work in the social sciences, had been well and truly taken up. During a discussion regarding the conceptual and methodological challenges of connecting local, seemingly mundane everyday livelihood strategies to wider global processes, while one speaker suggested researchers try to isolate "the concrete or material manifestations of the ideas we are talking about", other participants pointed towards the scope to employ non-representational theories in research with youth.

To some the observation that research concerning young people is becoming more theoretically informed and that it will continue to do so in the future would appear self-evident. What was certainly less clear after listening to discussions at the workshop is how this theoretically informed future will look. It was widely felt that increased theoretical engagement will be to the benefit of the field, provided we as researchers do not lose sight of the unique empirical insights garnered from working directly with young people. In many cases doing so not only revitalises the often mundane everyday life of the researcher, but the prevalence of interactive ethnographic and grounded approaches often facilitate a more productive engagement with theory. Workshop participants agreed that participatory approaches are particularly well suited to combining 
both 'usefulness' and scope for enriching youth geographies theoretically. In addition to this it was felt that greater collaboration with practitioners, and or those who straddle the spheres of practice and academia could in fact advance intellectual enquiry while contributing to public policy, social action or young people's everyday lives. Participants widely felt that the two need not be mutually exclusive.

This last point is particularly fitting in light of the time at which we are writing this review - in the aftermath of the 'riots' in August 2011 that centred on London but spread to several other UK cities, where the term 'youth' was applied by the media to all the perceived protagonists, overlooking the conspicuous presence of many 'adult' looters. The use of 'youth' as an umbrella term for this collective of, at best, disenfranchised troublemakers, at worst, hardened criminals (depending on the source of the news coverage), merely crystallised in the public's shared imagination the image of youth as the 'problem'. These events offer youth researchers two timely reminders: first, the importance of working with young people - and others within and beyond academia - to understand and communicate the increasingly complex challenges they face; and, second, to be aware of how our research contributes to perceptions of youth, at the same time as being sensitive to how the changing nature of young lives might call for the reframing of how we as researchers attempt to theorise them. In order to gain the clearest possible view when we look 'out' into young people's worlds, we also need to look 'in' to consider how we might define and deploy our terms appropriately.

\section{References:}

Cahill, C., 2007. Doing research with young people: participatory research and the rituals of collective work.

Children's Geographies, 5(3), pp.297-312.
As youth geographers engaging with young lives in very different ways, we developed Youth In Motion not only as a forum to stimulate geographical thinking about youth, but also to connect with youth researchers beyond our own discipline. As such, we aimed to respond directly to Evans' (2008) recommendation that geographers concerned with young people need to speak back to other social sciences, as well as beyond the academy into the public policy arena in which youth are increasingly positioned at the centre. And as the concluding sentiments of the Youth In Motion participants made clear, this will only be possible if in our attempts to become theoretically novel and fashionable, researchers do not leave the young people supposedly at the centre of their work behind.

\section{Acknowledgments:}

We would like to thank all of the workshop attendees. A full participant list can be found at http://youthinmotion.blogspot.com.

The UCL Youth Geographies Research Group was founded in September 2010 by the authors. 
Evans, B., 2008. Geographies of Youth/Young People. Geography Compass, 2(5), pp.1659-1680.

Hopkins, P. \& Pain, R., 2007. Geographies of age: thinking relationally. Area, 39(3), pp.287-294.

Horton, J. \& Kraftl, P., 2005. For more-than-usefulness: six overlapping points about children's geographies.

Children's Geographies, 3(2), pp.131-143

Horton, J. \& Kraftl, P., 2006. What else? Some more ways of thinking and doing "children's geographies." Children's Geographies, 4(1), pp.69-95.

Jeffrey, C., 2010. Geographies of children and youth I: eroding maps of life. Progress in Human Geography, 34(4), pp.496-505.

Jeffrey, C., 2011. Geographies of children and youth II: Global youth agency. Progress in Human Geography, 35(4), pp.1-9.

Skelton, T. \& Valentine, G. (Eds), 1998. Cool places: Geographies of youth cultures, London: Routledge 